\title{
Arbor
}

\section{La Universidad de Salamanca y el estudio del Derecho Penal ${ }^{1}$}

\section{Ignacio Berdugo Gómez de la Torre}

Arbor CLXXIII, 683-684 (Noviembre-Diciembre 2002), 513-520 pp.

Tres son las grandes preguntas que nos formulamos aquellos que nos dedicamos al estudio del Derecho Penal: cuál es el fundamento del derecho de castigar, qué contenido deben tener las leyes y qué interpretación debe darse a las normas para facilitar su aplicación. Una universidad casi ocho veces centenaria como la de Salamanca, que nació en torno al estudio del derecho — de ambos derechos: el de la Iglesia y el del Estado- ha tenido a lo largo de los tiempos como profesores de su claustro a figuras emblemáticas por la importancia de sus aportaciones a la respuesta a ese triple grupo de cuestiones. Este trabajo pretende revisar cuatro momentos históricos en los que en las aulas salmantinas se llevaron a cabo reflexiones que en buena medida condicionan todavía hoy el pensamiento jurídico penal español.

Aunque el penalista aborde hoy los tres grupos de preguntas, el debate sobre las mismas surge en el tiempo por condicionantes histórico-políticos en el orden antes expuesto. Primero las interrogantes sobre el fundamento, después el estudio sobre el contenido de las leyes y, finalmente, la investigación sobre los criterios de aplicación de las mismas. El examen sucesivo de las tres nos permitirá aproximarnos también a la evolución del estudio del Derecho Penal con la inevitable referencia a la historia del viejo Estudio Salmantino.

\section{I}

En el siglo XVI, en pleno auge de la Universidad de Salamanca, profesaba en sus aulas Alfonso de Castro, quien realizó una importante 
aportación sobre el derecho de castigar contenida en De potestate legis penalis, sin duda su obra clave. La respuesta al por qué del derecho de castigar viene ligada necesariamente al origen adjudicado al poder soberano. La vinculación a la divinidad del poder del monarca conducía necesariamente a la identidad delito-pecado. Un comportamiento es delictivo porque es pecado, "quia pecatum est».

Sobre este principio polemizan Alfonso de Castro y Martín de Azpilcueta. Disienten a propósito de la obligatoriedad moral o no de las leyes penales, pues esto parecía evidente en la apuntada identificación entre delito y pecado. En el marco de esta discusión apunta Alfonso de Castro la existencia de las denominadas «leyes meramente penales aquellas que contienen comportamientos cuya realización no supone una conducta pecaminosa, sino únicamente una desobediencia al poder del soberano». Se rompe con ello la identidad delito-pecado, lo que supone también un quiebre en el funcionamiento divino del origen del poder. La brecha abierta por estas consideraciones pueden hoy trasladarse a la relación ética-derecho en el ámbito de las conductas delictivas.

Alfonso de Castro lleva a cabo también otras reflexiones generales sobre temas penales. Algunas de ellas todavía hoy son plenamente válidas; recuérdese su consideración del carácter subsidiario del Derecho Penal al afirmar gráficamente que sus normas son «las almenas y los cañones de los demás derechos».

La Universidad y la enseñanza estaban en aquel tiempo fuertemente impregnadas por la religión. También, en buena medida, la vida política y las relaciones interestatales aparecían condicionadas por el hecho religioso. En este sentido, se producen en aquella época una serie de acontecimientos con trascendencia a medio y largo plazo sobre la historia de la Universidad. En 1492, año clave para la historia española -es el año de la conquista de Granada y del descubrimiento de América-, se lleva a cabo la expulsión de los judíos, cuya influencia era grande en la generación del saber en el Estudio Salmantino. La figura de Abraham Zacut, rabino, astrónomo y matemático, simboliza a todos los expulsados de forma sobrada.

La Universidad, por otro lado, vive un momento de extraordinario auge, pues es la Universidad de la monarquía. Simbólicamente, alrededor del medallón de la fachada plateresca que contiene las figuras de los Reyes Católicos aparece la siguiente inscripción «La Universidad por los Reyes, los Reyes por la Universidad». La Universidad, pese a ello, mantuvo la autonomía de su pensamiento frente al poder real; recuérdese, sin más, la elaboración del derecho de gente por Francisco 
de Vitoria. En aquel momento de auge esos privilegios del modelo salmantino eran espejo y aspiración para las fundaciones universitarias que se llevaban a cabo en la América recién descubierta; piénsese, por ejemplo, en el contenido de los documentos fundacionales de la Universidad Mayor de San Marcos (Perú). La Universidad de Salamanca es también la que tuvo como rectores, entre otros, al Conde Duque de Olivares y a D. Pedro Lagasca. Asimismo, constituía a través de sus cuatro Colegios Mayores la fuente clave para el personal que formaba la élite de la administración española.

Sin embargo, en sentido opuesto, la intolerancia religiosa en la España de la contrarreforma comenzaba a oscurecer el horizonte universitario. En general no puede olvidarse la prohibición a todos los españoles en la época de Felipe II de cursar estudios en las universidades europeas o, en el Estudio Salmantino, la prisión inquisitorial de Fray Luis de León, el traductor del Cantar de los Cantares.

\section{II}

El siglo XVIII se abre en España con la entronización de una nueva dinastía. La España de los Borbones va a asistir a un descenso imparable de su peso internacional y, en el ámbito universitario, a las primeras intervenciones directas de la Corona en la organización de las universidades, fruto de la influencia del Pensamiento Ilustrado. El sistema universitario, por entonces ya en total decadencia, es críticamente analizado por el ministro Jovellanos, pues ni su estructura ni el contenido de sus enseñanzas favorecían la difusión de las nuevas corrientes del saber en las aulas españolas, dificultado todo aún más por la intervención de la Santa Inquisición. Pese a ello, en América, las aulas universitarias eran en muchos casos cauce para las nuevas corrientes del pensamiento liberal que formarían los cuadros que protagonizarían años más tarde la Independencia.

La segunda mitad del siglo XVIII trae de la mano de la Ilustración el cuestionamiento del origen del poder, materializando en la Revolución Francesa el primer gran momento de laicización del fundamento del derecho, al trasladar la soberanía de la divinidad al pueblo. Las declaraciones de derechos del hombre exteriorizan de forma clara el giro que comienza a experimentar el Estado, su fundamento y sus fines. En el ámbito del Derecho Penal las consecuencias del cambio comienzan a percibirse en el alegato contra el derecho de las monarquías absolutas 
que supone el libro de Beccaría (traducido al español y prohibido por la Inquisición).

En realidad, se abre un nuevo periodo de carácter general en el ámbito jurídico, el del Estado Liberal, que formalmente se vincula al imperio de una ley emanada de la voluntad popular, a la que se sujeta el propio soberano y que se exterioriza en la promulgación de constituciones. Estas últimas predican formalmente los derechos del hombre y la división de poderes y, además, se materializan en la elaboración de códigos que sustituyen a las viejas compilaciones.

En este nuevo marco y en el campo del Derecho Penal, a la pregunta del por qué se añade como imperativo la concerniente al contenido de las leyes, la elaboración de códigos.

A finales del siglo XVIII llega a Salamanca un aragonés, Ramón Salas, estudiante de doctorado, que había cursado estudios en San Carlos de Guatemala. Tras obtener el grado de Doctor en el Estudio Salamantino es nombrado rector del mismo y pasa a ocupar más tarde la cátedra de economía en la Facultad de Derecho, lo que era una novedad en el Viejo Estudio. Desde su cátedra Salas se vuelve el alma del Colegio de Filosofía, de sus reuniones y debates, y a través del mismo, es la persona clave que da entrada a las nuevas corrientes del pensamiento liberal. Ramón Salas tradujo del francés la obra de Jeremías Bentham, que defiende con entusiasmo Toribio Núñez, compañero de Claustro de la Facultad de Derecho y bibliotecario de la Universidad. La influencia de los libros de Bentham es decisiva tanto en la América hispana como en la España del siglo XIX, que dramáticamente comienza a debatirse entre absolutistas y liberales.

Ramón Salas, al que Menéndez Pelayo califica de volteriano y descreído, fue denunciado en 1796 por un compañero de facultad, Poveda, ante la Inquisición. Procesado por el Santo Oficio, fue desterrado de Salamanca y Madrid y perdió su cátedra que nunca recuperó. Salas, que continúa su labor de traductor e introductor del pensamiento liberal hasta su fallecimiento bien entrado el siglo XIX, es la persona clave para la incorporación de las nuevas ideas a la universidad española a través de la Universidad de Salamanca.

Políticamente, la obra de las Cortes de Cádiz en 1812 y, muy especialmente, la Constitución por ellas elaborada plasma por vez primera en España el Pensamiento Liberal. En las cortes gaditanas intervienen activamente muchos profesores salmantinos; no debe olvidarse que uno de ellos, Muñoz Torrero, antiguo rector, fue su primer presidente.

La elaboración de los códigos aparece como imperativo en el texto constitucional, aunque en el ámbito penal no se plasmará hasta el 
trienio liberal en 1822. La obra de Bentham, traducida y difundida desde Salamanca, fue clave en el contenido de este primer código. Baste con recordar el contenido de los informes elaborados por las distintas universidades - el de Salamanca, por cierto, obra de Toribio Núñez. En alguno de ellos, el de Sevilla, no se dudaba en calificar como «infalible» la obra del pensador inglés.

El código de 1822, influido por Bentham -aunque si nos remitimos a la correspondencia que este mantuvo con el Conde de Toreno, no tanto como éste hubiera deseado-, tuvo una efímera vigencia en España. Poco tiempo después fue derogado con el regreso del absolutismo de la mano de los cien mil hijos de San Luis, aunque tuvo una importante influencia tanto en los posteriores códigos españoles como en muchos americanos.

\section{III}

El siglo XIX en España es dramático, a la pérdida de peso internacional se une una crisis política, económica y cultural. España es un país atrasado y marcado por los enfrentamientos civiles. El sistema universitario se reduce, padeciendo los efectos de la desamortización. Mediado el siglo, la Ley Moyano limita a la Universidad Central, «la única que en verdad merece el nombre de universidad», la posibilidad de conceder el título de Doctor. No obstante, mediado el siglo también un grupo de universitarios formado en las aulas y doctrinas surgidas en las universidades centro-europeas, lo que era excepcional, funda la Institución Libre de Enseñanza, que va a ser el germen del despertar de la intelectualidad española en las siguientes décadas.

La Universidad de Salamanca vive en este siglo la crisis más importante de su historia, con un descenso importantísimo de alumnos, en una ciudad no recuperada de las heridas de la Guerra de Independencia, y sometida a depuración ideológica por los gobiernos absolutistas, la universidad está a punto de ser cerrada. Sólo a partir de 1868 y hasta 1900 en el largo Rectorado de Mamés Esperabé comienza una lenta recuperación, producida sin duda por la incorporación a su Claustro, en la época de la restauración, de dos figuras claves de la intelectualidad de la época: Miguel de Unamuno y Dorado Montero.

En el ámbito penal, el siglo XIX es el siglo de la codificación, principal aportación en nuestro ámbito cultural de la denominada Escuela Clásica. En España, el Código de 1848 es la pieza clave que, con diversas revisiones consecuencia de los cambios políticos de nuestra 
historia, llega hasta 1995. Elaborada la ley, el estudio del derecho penal se materializa sólo en comentarios realizados por prácticos del derecho penal.

Mediado el siglo, el progreso generalizado que se vive en Europa vinculado al auge de las ciencias experimentales abre un periodo de cientificismo con consecuencias en el ámbito jurídico. En el campo del estudio del Derecho, una vez dotada la legislación de la estabilidad que proporcionan los códigos, debe aplicarse el método científico, el de las ciencias experimentales, sobre esta realidad que son las normas. La consecuencia de esta situación es el positivismo jurídico, en el que la preocupación de los juristas deja de ser qué contenido deben tener las leyes penales para pasar a ser al examen de dicho contenido así como la creación de un sistema que facilite a los jueces su aplicación y refuerce la seguridad jurídica que esperan obtener los ciudadanos. El positivismo jurídico se instala en Alemania, y en menor medida en Italia, y no llega a las aulas españolas y salmantinas hasta las primeras décadas del siglo XIX.

Paralelamente, la proyección del método de las ciencias experimentales sobre la realidad social e individual del delito, reabre las preguntas del fundamento del derecho de castigar y del contenido que deben tener las leyes penales.

En la España de la Restauración, este último positivismo, el criminológico, se mezcla con componentes que vienen del pensamiento correccionalista y tiene su máximo representante en un profesor salmantino, Pedro Dorado Montero. Éste se incorpora a la cátedra en 1893, a la vez que lo hace un joven profesor de Griego, Miguel de Unamuno.

La biografía universitaria de Dorado Montero, defensor de un pensamiento laico en una universidad que no lo era y con una obra que supone una isla en el desolado panorama universitario de entonces, es todavía un ejemplo para todos los que profesamos en las aulas salmantinas.

Dorado parte de un estado intervencionista y construye un Derecho Penal que, en cuanto genera consecuencias favorables para ese enfermo no libre que es el delincuente, se torna en derecho protector de los criminales. Con ello traslada de alguna manera al Derecho Penal la relación médico (el juez) / paciente (el delincuente). Construye un sistema utópico, lo que ha sido calificado por los estudiosos de su obra como «la utopía penal de Dorado Montero».

Dorado abre, además, otra vía en la doctrina penal española con un importante trabajo como traductor de los más relevantes autores 
italianos y alemanes de la época. Pedro Dorado Montero tuvo influencia sobre toda la doctrina española, aunque su sistema utópico, al igual que el de los positivistas criminológicos, no tuvo una proyección directa sobre las normas penales, pues las garantías vinculadas al estado liberal de derecho se tornan irrenunciables, como dramáticamente pone de manifiesto la historia de nuestros pueblos. La obra de Dorado influye en los primeros trabajos de Jiménez de Asúa, en especial en su tesis doctoral «la sentencia indeterminada».

IV

Luis Jiménez de Asúa es el autor clave para el inicio y difusión de la aplicación del método de las ciencias experimentales al estudio del Derecho Penal. La dogmática comienza a estudiarse en los países de habla hispana a través de la primera traducción y notas del Tratado de Von Liszt, que lleva a cabo Jiménez de Asúa, junto con Saldaña. Más tarde es muy relevante su discurso de apertura en la Universidad Central y toda su obra y magisterio a ambos lados del Atlántico. Junto a la aportación de Luis Jiménez de Asúa es decisiva, para la evolución de la dogmática en España, la traducción y notas que lleva a cabo Rodríguez Muños del Tratado de Mezger. De alguna forma, en mayor o menor medida, todos hemos bebido en esas fuentes.

Al final de la década de los años veinte se incorpora a la cátedra salmantina de Derecho Penal, un joven profesor madrileño, José Antón Oneca, que años más tarde, en 1949, publicaría una parte general de Derecho Penal que es clave en la docencia española. Este libro sólido y claro marca una época en el estudio del Derecho Penal y condiciona durante décadas la práctica de los tribunales españoles.

Antón tiene, además, estudios muy relevantes sobre diversos delitos de la parte especial, los fines de la pena o la historia de la codificación española. Gran parte de la doctrina española, en mayor o menor medida, somos discípulos de José Antón Oneca.

Antón Oneca es, sin lugar a dudas, una figura clave para entender el actual desarrollo y nivel del Derecho Penal Español. Pero además, la vida académica de Antón Oneca es reveladora de toda una época. Tal como he apuntado, se incorpora muy joven a la cátedra de Salamanca. Con la llegada de la Segunda República pasa a desempeñar un puesto de magistrado del Tribunal Supremo, donde deja su huella con la incorporación, por ejemplo, de la entonces novedosa Teoría de la causalidad adecuada. Finalizada la guerra es depurado, pierde la 
cátedra, sufre trabajos forzados y empieza a vivir lo que se ha llamado el exilio interior. Años más tarde, recuperada la cátedra salmantina, permanece en Salamanca hasta los años sesenta, cuando pasa a la Universidad Complutense. Jubilado y respetado por todos, en un último guiño de la historia, muere el 23 de febrero de 1981.

Antón dejó huella en Salamanca, en su universidad y en toda la universidad española. Hoy paralelamente a la recuperación de la democracia, la universidad española ha recuperado su autonomía. La universidad, y muy simbólicamente la de Salamanca, poco tiene que ver con la que hace un siglo presidía Unamuno, tanto en dimensión cuantitativa como cualitativa, en presencia nacional y en relaciones internacionales. Ha sido, sin duda, un cambio paralelo al que ha experimentado España. De igual manera, aquel viejo Código Liberal de 1848 ha sido sustituido en 1995 por el denominado Código Penal de la Democracia.

Hoy, los estudiosos de Derecho Penal continuamos intentando responder a las tres preguntas con las que inicié esta breve exposición: por qué el derecho de castigar, qué contenido deben tener las leyes y cómo debemos aplicarlas. Las tres preguntas sirven de marco, creo, a todas las interrogantes que un penalista debe continuar planteándose.

\section{Notas}

1 Texto del discurso de recepción de Doctorado Honoris Causa por la Universidad Nacional Mayor de San Juan Marcos, Lima (julio 2002). 